\title{
ЗДОРОВЬЕ ДЕТСКОГО НАСЕЛЕНИЯ, ПРОЖИВАЮЩЕГО В ЗОНЕ ДЕЙСТВИЯ КРУПНОГО МЕДЕПЛАВИЛЬНОГО КОМБИНАТА
}

\author{
Г.Н. Киреева ${ }^{1}$, Е.В. Жуковская ${ }^{2 *}$ \\ ${ }^{1}$ Областная детская клиническая больница, г. Челябинск, Россия \\ ${ }^{2}$ НМИЦ детской гематологии, онкологии и иммунологии им. Д. Рогачева, МЗ России, Москва, Россия \\ *e-mail: elena_zhukovskay@mail.ru
}

РЕЗЮМЕ. Проживание на территории с избыточным уровнем химических элементов может сказываться на различных функциях организма на протяжении всей жизни человека. Целью настоявшего исследования была оценка здоровья детского населения г. Карабаша, и контаминации организма обследуемых детей токсичными и условно токсичными химическими элементами. В 2014 г. проведено клиническое обследование 114 детей от 12 до 14 лет, проживающих на территории Челябинской области в г. Карабаше, и исследованы пробы волос на содержание макро- и микроэлементов. Аналитические исследования выполнены в испытательной лаборатории АНО «Центр биотической медицины» методами атомной эмиссионной спектрометрии с индукционно связанной аргоновой плазмой (ИСП-АЭС) и другими. Выявлены отклонения сердечно-сосудистой и нервной систем, высокая частота коморбидных заболеваний. Мальчики в большей степени имеют избыток As, Cd, Tl, а девочки - избыток $\mathrm{Pb}$. Содержание в волосах испытуемых из г. Карабаша As и Рb выше по сравнению не только с показателями детей из других населенных пунктов, но и с рекомендуемыми среднероссийскими значениями.

КЛЮЧЕВЫЕ СЛОВА: дети, здоровье, токсичные, эссенциальные химические элементы.

\section{HEALTH OF CHILDREN LIVING IN THE AREA OF OPERATION OF A LARGE COPPER SMELTER}

\author{
G.N. Kireeva ${ }^{1}$, E.V. Zhyukovskfya ${ }^{2 *}$ \\ ${ }^{1}$ Regional Children's Clinical Hospital, Chelyabinsk, Russia \\ ${ }^{2}$ NMIC of Children's Hematology, Oncology and Immunology named after D. Rogachev, \\ Ministry of Health of Russia, Moscow, Russia \\ *e-mail: elena_zhukovskay@mail.ru
}

\begin{abstract}
Living in an area with excessive levels of chemical elements can affect various body functions throughout a person's life. The purpose of this study was to assess the health of the child population of the city of Karabash, and the contamination of the organism of the examined children with toxic and conditionally toxic chemical elements. In 2014, a clinical examination was carried out on 114 children from 12 to 14 years old, living in the Chelyabinsk region in the village of Karabash, and hair samples were examined for the content of macro- and microelements. Analytical studies were carried out in the Testing Laboratory of ANO "Center for Biotic Medicine" by methods of atomic emission spectrometry with inductively coupled argon plasma (ICP-AES) and others. Deviations of the cardiovascular and nervous systems, a high incidence of comorbid diseases were revealed. Boys have an excess of As, Cd, Tl largely, while the girls have an excess of $\mathrm{Pb}$. The content of $\mathrm{As}$ and $\mathrm{Pb}$ in the hair of subjects from Karabash is higher not only with the indicators of children from other settlements, but also with the recommended average Russian values. Conclusion. The indicators of the health of the child population, the increased content of toxic chemical elements in biomaterials make it possible to classify Karabash as a city in need of recreational programs.
\end{abstract}

KEYWORDS: children, health, toxic, essential chemical elements.

\section{ВВЕДЕНИЕ}

Основная часть патологии как детского, так и взрослого населения имеет полигенную природу. Реализация генетический детерминированных рисков зависит от комплекса причин эндогенной и полигенной природы. Если существование моногорода связано с объектом тяжелой или цветной металлургии, то весьма вероятной становится повышенная нагрузка токсичными металлами на внешнюю среду и организм человека. К подобным территориям относится г. Карабаш в Челябинской области.

Ксенобиотический профиль биогеоценоза у человека реализуется путем формирования доклинических или патологических проявлений микроэлементозов (Царегородцева и др., 2011). Дефицит или избыток микроэлементов может сказываться на различных функциях организма на 
протяжении всей жизни человека. Таким образом, приобретенный в детстве микроэлементоз может иметь долгосрочные последствия (Barr et al., 2001; Бондаренко, Киреева, 2014).

Учитывая почти двухсотлетнюю историю добычи и переработки промышленных золотоносных и медесодержащих руд, напряженную социальную ситуацию, интерес к здоровью детского населения не угасает.

Цель исследования - оценка здоровья детского населения г. Карабаша и контаминация организма обследуемых детей токсичными и условно токсичными химическими элементами.

\section{МАТЕРИАЛЫ И МЕТОДЫ}

В поперечном исследовании в 2014 г. изучены образцы волос 114 детей (учеников средних общеобразовательных учреждений возрастом от 12 до 14 лет, проживающих на территории Челябинской области в г. Карабаше) на содержание макро- и микроэлементов

Оценка состояния здоровья включала врачебный осмотр (педиатр, стоматолог), определение антропометрических характеристик, ЭКГ, спирометрию, пульсоксиметрию, экспресс-анализ общего холестерина и глюкозы в крови, определение факторов риска развития социально значимых заболеваний. Индикативные показатели здравоохранения были предоставлены органами областного и муниципального здравоохранения.

Аналитические исследования выполнены в испытательной лаборатории АНО «Центр биотической медицины» (Москва) методами атомной эмиссионной спектрометрии с индукционно связанной аргоновой плазмой (ИСП-АЭС) и масс-спектрометрии с индуктивно связанной аргоновой плазмой (ИСП-МС) на приборах Optima 2000 DV, Elan 9000 и NexION 300D+NWR213 (Perkin Elmer, CША).

Математическая обработка результатов исследования с учетом данных общей оценки здоровья и функционального состояния организма проведена с помощью программы STATISTICA 8.0 (StatSoft Inc., США).

\section{РЕЗУЛЬТАТЫ И ОБСУЖДЕНИЕ}

Общеклиническое обследование мальчиков и девочек позволило охарактеризовать сформированную группу школьников, как соответствующую средненормативным показателям. Большинство подростков имели мезосоматотип. Из соматических проявлений можно отметить лабильность числа сердечных сокращений, повышенное содержание глюкозы, у 12 мальчиков и 3 девочек уровень холестерина превышал нормативы. Причиной изменений может служить значительное число факторов: от времени забора биопроб до наличия у подростков эндокринной патологии, вегетативных нарушений. Всем детям было предложено пройти обследование в областной детской больнице в гастроэнтерологическом и эндокринологическом отделениях. Таким образом, $33(25,4 \%)$ школьника имели третью группу здоровья. В 2020 г. доля детей в возрасте до 17 лет с первично установленным диагнозом болезней костно-мышечной системы и соединительной ткани составила $78 \%$ при величине индикативного показателя 40\%. Такие же пропорции характерны для эндокринной патологии болезней системы органов кровообращения и др.

В какой степени на это влияют социально-медицинские условия г. Карабаша (обеспеченность врачебными кадрами 30\%), образ жизни и т.п.? Но нельзя не сказать, что население проживает в условиях техногенного прессинга.

Как показали результаты эксперимента, дети, проживающие в г. Карабаше, наряду с характерным для всех обследований дефицитом эссенциальных элементов испытывают повышенную нагрузку комплексом токсичных, потенциально токсичных металлов и As по сравнению со сверстниками из других населенных пунктов (Скальный, Демидов, 2001). При этом мальчики в большей степени страдают от избытков $\mathrm{As}, \mathrm{Cd}, \mathrm{Tl}$, а девочки - от избытка $\mathrm{Pb}$. Содержание в волосах испытуемых из г. Карабаша $\mathrm{As} \mathrm{и} \mathrm{Pb}$ выше по сравнению не только с показателями детей из других населенных пунктов, но и с рекомендуемыми среднероссийскими значениями (Нотова и др., 2017). 
Аномалии содержания в волосах токсичных элементов и дефицит эссециальных элементов подтверждают общебиологические закономерности промышленной токсикологии, независимо, идет ли речь о небольшом городе с предприятием, загрязняющую среду или о мегаполисах Москва, Челябинск (Узунова, Аксенов, 2015). Однако распространенность избытка As, Cd, Pb у детского населения г. Карабаша превосходит города миллионники.

\section{ВЫВОДЫ}

Моногорода могут решать свои экологические проблемы с помощью областных или федеральных властей, использование же их в качестве модели позволяет с меньшими затратами разрабатывать внедрять эффективные рекреационные программы для регионов (Драчук и др., 2016).

\section{Список литературы}

1. Царегородцева А.Д., Викторова А.А., Османова И.М. (ред.). Экологическая педиатрия. М: Триада-Х. 2011.328 с.

2. Бондаренко В.П., Киреева Г.Н. Методы лабораторной диагностики здоровья детей в экологически неблагоприятных райнах. Материалы междисциплинарной НПК «Здоровье населения промышленных моногородов». Челябинск, 2014. С. 13-16.

3. Barr D.B, Wang R.Y., Needman L.I. Biologic monitoring of exposure to environmental chemicals throughout the life stages: Requirements and issues for consideration for the National Children's Study. Environ. HealthPerspect. 2005; 113(8): $1083-1091$.

4. Скальный А.В., Демидов В.А. Элементный состав волос как отражение сезонных колебаний обеспеченности организма детей макро- и микроэлементами. Микроэлементы в медицине. 2001; 2(1): 36-41.

5. Нотова С.В., Киреева Г.Н., Жуковская Е.В., Грабеклис А.Р., Кияева Е.В., Скальный А.В., Дерягина Л.Е. Влияние антропогенных и геохимических факторов среды обитания на элементный статус детей челябинской области. Экология человека. 2017; 11: 23-28.

6. Узунова А.Н., Аксенов А.В. Значимость изменений содержания тяжелых металлов в сыворотке крови при ювенильном артрите у детей, проживающих в крупном промышленном центре Южного Урала - Челябинске. Педиатрический вестник Южного Урала. 2015; 1: 48-517.

7. Драчук Л.А., Драчук Т.Э., Пешикова М.В. Рациональное использование медико-статистических исследований в практическом здравоохранении. Педиатрический вестник Южного Урала. 2016; 2: 78-85.

\section{References}

1. Caregorodceva A.D., Viktorova A.A., Osmanova I.M. (red.). Jekologicheskaja pediatrija. M: Triada-H. $2011.328 \mathrm{~s}$.

2. Bondarenko V.P., Kireeva G.N. Metody laboratornoj diagnostiki zdorov'ja detej v jekologicheski neblagoprijatnyh rajnah. Materialy mezhdisciplinarnoj NPK «Zdorov'e naselenija promyshlennyh monogorodov». Cheljabinsk, 2014. S. 13-16.

3. Barr D.B, Wang R.Y., Needman L.I. Biologic monitoring of exposure to environmental chemicals throughout the life stages: Requirements and issues for consideration for the National Children's Study. Environ. HealthPerspect. 2005; 113(8): $1083-1091$.

4. Skalnyj A.V., Demidov V.A. Jelementnyj sostav volos kak otrazhenie sezonnyh kolebanij obespechennosti organizma detej makroi mikrojelementami. Mikrojelementy v medicine. 2001; 2(1): 36-41.

5. Notova S.V., Kireeva G.N., Zhukovskaja E.V., Grabeklis A.R., Kijaeva E.V., Skalnyj A.V., Derjagina L.E. Vlijanie antropogennyh i geohimicheskih faktorov sredy obitanija na jelementnyj status detej cheljabinskoj oblasti. Jekologija cheloveka. 2017; 11: 23-28.

6. Uzunova A.N., Aksenov A.V. Znachimost' izmenenij soderzhanija tjazhelyh metallov v syvorotke krovi pri juvenil'nom artrite u detej, prozhivajushhih v krupnom promyshlennom centre Juzhnogo Urala - Cheljabinske. Pediatricheskij vestnik Juzhnogo Urala. 2015; 1: 48-517.

7. Drachuk L.A., Drachuk T.Je., Peshikova M.V. Racional'noe ispol'zovanie mediko-statisticheskih issledovanij v prakticheskom zdravoohranenii. Pediatricheskij vestnik Juzhnogo Urala. 2016; 2: 78-85. 